\title{
MODELING AND ANALYSIS OF A THREE STAGE MULTI- PERIOD SUPPLY CHAIN
}

\author{
M. S. Abass ${ }^{\mathrm{a}}$, A.M. Gaafer ${ }^{\mathrm{b}}$, A. R. Saad ${ }^{\mathrm{b}}$. \\ ${ }^{a}$ Faculty of Engineering, Modern University, Egypt. \\ ${ }^{\mathbf{b}}$ Mechanical Department, Faculty of Engineering, Benha University, Egypt.
}

\begin{abstract}
In today's highly competitive environment, an effective supplier selection process is very important to the success of any manufacturing organization. In this context, supplier selection represents one of the most important functions to be performed by the purchasing department. This paper presents a supplier selection problem along with an integrated multi objective, multiproduct, multi period model under hybrid Make-To-Stock (MTS)/Make-To-Order (MTO) production strategy. The model consists of manufacturer, multi-product, multi distributer, and multi-supplier. The objective of the model is to minimize the total cost, minimize the total delivery time, and maximize the facility utilization involved in running supply chain via Fuzzy Goal Programming (FGP) approach. The model is tested with a set of realistic data and the optimal results show that most of strategic and tactical decisions are obtained. So the model is validated and provided useful tool to select the optimal supplier.
\end{abstract}

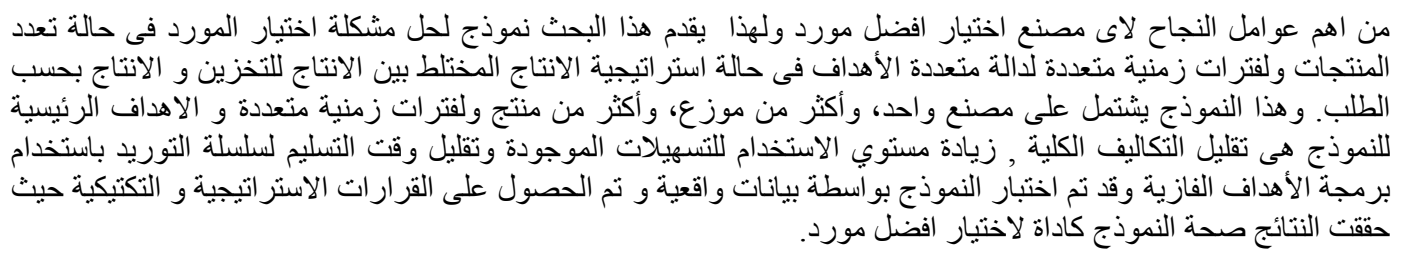

Keywords: Supply Chain, Production-Inventory-Distribution integration, Hybrid MTS/MTO, Supplier Selection, multi objectives function.

\section{Introduction}

Supplier selection is the process by which the buyer identifies, evaluates, and contracts with suppliers. The challenges mentioned above make supplier selection a fertile topic for operations and management science disciplines. The selection of suppliers plays a key role in an organization because the cost of raw material constitutes the main cost of the final product. Many experts believe that the supplier selection is the most important activity of a purchasing department [1].

Supplier selection is complicated by the need to consider various criteria. According to academicians and purchasing managers, there are many criterions that are important in the supplier decision process. Quality, cost, and delivery performance history are identified as the three most important criteria in supplier selection. Production

facilities and capacity, technical capability and geographical location were also identified as important criteria.

Many previous studies have been conducted, in which the criteria and methodologies for supplier selection were discussed.

One of the most significant ones, focused on analysis of measureable criteria for supplier 
selection, was made by Dickson [2].He examined the importance of supplier evaluation criteria and presented 23 supplier attributes that managers consider in such an evaluation. In their survey identified

quality, cost and on-time delivery as the most important supplier selection criteria in the evaluation of supplier performance. In addition, Kermani et al investigated the methodologies for supplier selection [4].

A brief review of some of the articles discussing supplier selection as a whole is presented below.

Kokangul and Susuz [5] apply an integration of analytical hierarchy process and non-linear integer and multi-objective programming under some constraints such as quantity discounts, capacity, and budget to determine the best suppliers and to place the optimal order quantities among them. Their integration-based multi-criteria decision making methodology takes into account both qualitative and quantitative factors in supplier selection. Dursun and Karsak[6] developed a fuzzy multi-criteria group decision making approach that makes use of the quality function deployment (QFD) concept for supplier selection process. Adeinat and Ventur [7] presented a mixed integer nonlinear programming model to find the optimal replenishment policy for a particular type of product for the case of a single retailer and multiple potential suppliers. Mendoza and Ventur [8] a two mixed integer nonlinear programming models are proposed to select the best set of suppliers and determine the proper allocation of order quantities while minimizing the annual ordering, inventory holding, and purchasing costs under suppliers' capacity and quality constraints.

Shirkouhi et al. [9] aim to solve a supplier selection problem under multi-price level and multi-product using interactive two-phase fuzzy multi-objective linear programming (FMOLP) model. The piecewise linear membership functions are applied to represent the decision maker's fuzzy goals for the supplier selection and order allocation problem resulting in more flexibility via an interactive decision-making process. Huseyin Selcuk Kilican[10] developed an integrated approach including fuzzy Technique for Order Preference by Similarity to Ideal Solution (TOPSIS) and a mixed integer linear programming model to select the best supplier in a multiitem/multi-supplier environment.

On the other hand Mafakheri et al.[11] proposed a two-stage multiple criteria dynamic programming approach for two of the most critical tasks in supply chain management, namely, supplier selection and order allocation. While Elahi et al [12] attempted to
Weber et al. [3] classified all published papers (since 1966) according to the studied criteria and they

take the quantity discount into consideration and proposed a multi- objective linear programming utilizing a fuzzy compromise programming in order to convert this problem to a single objective model and incorporate the weights of objectives through various decision makers' opinion.

a multiple sourcing supplier selection problem as a multi objective linear programming problem is considered by Arikan [13]. Three objective functions are minimization of costs, maximization of quality and maximization of on-time delivery respectively. He proposed a fuzzy mathematical model and a novel solution approach in order to solve the problem, to satisfy the decision maker's aspirations for fuzzy goals.

Liao and Pei Kao [14] integrate the Taguchi loss function, analytical hierarchy process (AHP) and multi-choice goal programming (MCGP) model for solving the supplier selection problem. The advantage of this proposed method is that it allows decision makers to set multiple aspiration levels for the decision criteria.

Lee et al. [15] develop a fuzzy multiple goal programming (FMGP) model to help downstream companies to select thin film transistor liquid crystal display (TFT-LCD) suppliers for cooperation. Fuzzy analytic hierarchy process (FAHP) is applied first to analyze the importance of multiple factors by incorporating experts' opinion, and these factors include cost, yield and number of suppliers. Multichoice goal programming is used next to consider the limits of various resources and to formulate the constraints.

Rong-Ho Lin[16] suggested a comprehensive decision method for identifying top suppliers by considering the effects of interdependence among the selection criteria, as well as to achieve optimal allocation of orders among the selected suppliers.

Woarawichai et al. [17] aim to calculate the optimal inventory lot-sizing for each supplier and minimize the total inventory cost which includes joint purchase cost of the products, transaction cost for the suppliers, and holding cost for remaining inventory. They applied the Genetic algorithms to the multiproduct and multi-period inventory lot-sizing problems with supplier selection under storage capacity. Also they considered a maximum storage capacity for the decision maker in each period. 
Aksoy and Nursel [18] aimed to aid just-in-time (JIT) manufacturers in selecting the most appropriate suppliers and in evaluating supplier performance. They presented neural a network based supplier selection and supplier performance evaluation systems. The proposed approach is not limited to JIT supply.

The supplier selection problem in presence of price breaks or discount schemes becomes more complicated. Suppliers sometimes offer discounts. The motivation for using discount schemes stems from the fact that it tends to encourage buyers to procure larger quantities and to obtain operating advantages (such as economies of scale or reducing the cost of transportation) for the buyer.

Amid et al. [19] developed a fuzzy multi objective model for the supplier selection problem under price breaks that depend on the sizes of order quantities. Through this model, purchase managers can assign different weights for numbers of criteria in order to manage flow of supply materials, components and finished products to improve quality, service and reduced cost, in order to make improvement in supply chain performance.

On the other hand Esfandiari and Seifbarghy [20] propose a multi-objective model in which purchasing cost, rejected units, and late delivered units are minimized, while the obtained total score from the supplier evaluation process is maximized. They assume that the buyer obtains multiple products from a number of predetermined suppliers. The buyer faces a stochastic demand with a probability distribution of Poisson regarding each product type. They assumed that the supplier prices are linearly dependent on the order size of each product. They use the well-known L-1 metric method to solve the supplier evaluation problem by utilizing two metaheuristic algorithms to solve the corresponding mathematical problems.

Ebrahim et al. [21] introduced a mathematical model considering different types of discount (all-unit cost, incremental discount, and total business volume discount) through multi-objective formulation for single item purchasing problem. In addition, constraints such as suppliers 'capacity and demand are taken into consideration in the model. They presented a proposed scatter search algorithm (SSA) to solve this problem. Chang and Lee [22] proposed a comparison Shopping Optimization Model based on Suppliers' Pricing Contexts (CSOM-SPC), which gives online consumers effective price-sorted suppliers.
A manufacturing system can be defined as an arrangement of tasks or processes to transform a selected group of raw materials or semi-finished products into a set of finished products. From the viewpoint of the relationship between production release and order arrival, production systems can be classified into Make-To-Stock (MTS) and Make-ToOrder (MTO) or Hybrid one. In a MTS system, the facility produces according to a forecast of customer demand. In a MTO system, the facility produces according to customer requests and no finished goods inventory is kept. Hybrid MTS/MTO production gain the advantages of the two strategies.

Some researches on the combined MTO-MTS planning used the Decoupling Point (DP) approach to distinguish the MTS and the MTO stages of a production system. Jan Olhager [23] investigates the impact of the position and role of the CODP on issues of concern for production and supply chain management. He proposes a dual design approach for production and supply chain planning systems; one type of system for operations upstream the CODP and another type of system for downstream operations in order to fully support the characteristics and objectives of each respective part of the supply chain. He also[24] discusses the impact of having the decoupling point at different positions, and the distinguishing features for value chain operations upstream the decoupling point versus those downstream the decoupling point.

While Sun et al. [25] used multiple DPs to partition the supply network. The components are made to stock from the upper supply network to the multiple DPs while the components are made to order from the multiple DPs to the end of the supply network. They mainly consider the effect of demand variance and customer delivery time for positioning multiple DPs. Also, H. Shidpour et al. [26] analyze impacts of single-CODP and multiple-CODP and develop two objective bases on company's profit customer values perceived on product variety with trade offing among two proposed objective under service time constraint.

The Customer Order Decoupling Point (CODP) or Order Penetration Point (OPP) in the production line is a point in the manufacturing value chain for a product, where the product is linked to a specific customer order and also divides the manufacturing stages that are forecast-driven from those customerorder-driven ones [27].

H. Rafiei and M. Rabbani [28] attempted to propose a new decision making structure to find solutions for two strategic issues in MTS/MTO systems including order partitioning and OPP location for each product family by considering the driving factors influencing these issues and fuzzy ANP as a decision making tool 
for finding the OPP locations. They also [29] address the strategic level of Hybrid Make-To-Stock (MTS)/Make-To-Order (MTO) production contexts using Fuzzy Analytic Network Process (FANP). But the decisions which are involved in this level are family formation and order partitioning.

Some other researches deal with end-products which having a common component, i.e: semi-finished product.

On the other hand Lmehdawe and Jewkes [30] consider a stochastic two-stage hybrid manufacturing system for a single product where semi- finished goods are Made-To-Stock (MTS) and then differentiated when demand is realized through a Make-To-Order (MTO) stage. They introduce a batch ordering policy to permit economies of scale in ordering due to a cost associated with each order placed. They use the Matrix-analytic method to evaluate system performance under this ordering policy. After wards, they develop an optimization model to find the optimal intermediate buffer size and the optimal replenishment order quantity for the system. They show that a base stock policy is subptimal in the presence of a replenishment cost for semi-finished goods.

The idea of switching between MTS and MTO production has been discussed by other researchers. Zhan et al. [31] develop an analytical model of a multiple-machine dynamic hybrid MTS-MTO facility which is capable of efficient standardized production and mass customization. They propose a simple policy for switching a select group of flexible machines between MTS and MTO production. H. Rafiei and M. Rabbani [32] combine the switching between MTS and MTO and OPP. They developed a model to first decide on which product is manufactured upon MTS, which one upon MTO and which one upon hybrid strategy. Then, a fuzzy analytic network process (ANP) is utilized to locate the OPP for the products which are decided to be manufactured upon hybrid strategy.

While Zaerpour et al. [33] present a strategic decision-making structure to determine whether a particular product should be produced under maketo-order (MTO) or make-to-stock (MTS) strategy. A novel hybrid methodology consisting of strengths, weaknesses, opportunities and threats (SWOT) analysis and analytic hierarchy process (AHP) is proposed. FAHP's connection to SWOT yields a novel hybrid method for partitioning of MTO/MTS products. Kaminsky and Kaya [34] integrate due date quotation with combined MTO-MTS decision making, consider several different approaches for sequencing jobs and focus on two-stage supply chain models. Their analysis provides guidance for deciding when to use MTS and when to use MTO approaches in supply chains, and how to effectively operate the systems to minimize system-wide costs. On the other hand Kalantari et al. [35] present a novel decision support system for order acceptance/rejection in a hybrid Make-toStock/Make-to-Order production environment. The proposed decision support system is comprised of five steps. Wu et al. [36] presentd a scheduling method for a hybrid MTO/MTS semiconductor fab imposed with machine-dedication constraints. The scheduling method involves two shop floor control decisions; releasing and dispatching.

Lower inventory cost and better customer service is the target of all approaches, although different approaches are used to control the production of hybrid MTO-MTS systems. This objective is achieved by integrating production planning and inventory control decisions.

Soman et al. [37] test the conceptual production planning and inventory control framework for combined make-to-order (MTO) and make-to-stock (MTS) production mode. They apply the framework in the case of a firm that produces 230 products on a single line with limited capacity. But In-Jae Jeong [38] propose a dynamic model to simultaneously determine the optimal position of the decoupling point and production-inventory plan in a supply chain such that the total cost of the deviation from the target production rate and the target inventory level is minimized using the optimal control theory. While Chang et al. [39] aimed to develop a heuristic activity control (PAC) model to achieve the different production criteria (for MTO and MTS) in the hybrid production environment. Eivazy et al. [40] present a dynamic production control and scheduling model for a semiconductor shop (fab) with hybrid MTS/MTO production environment. The proposed model encompasses two major modules: release module and dispatching module.

A mixed MTS/MTO policy is also considered by Khaled et al. [41] to manage a single manufacturing facility producing two classes of end-products, high volume demands (HV) and low volume demands (LV).They analyze and compare the impact of the choice of the scheduling policy on the overall performance of the system. They consider two policies: the classical a first-in-first-out (FIFO) policy and a priority policy (PR). They develop analytical/numerical solutions to optimize each system.

On the other hand Eltawil and Ghazal [42] presents an integrated production/inventory planning model. The model is employed within an Enterprise Resource Planning (ERP) system to generate 
feasible, constrained operational production plans and replenishment schedules. The model is applied to a process industry case of a single line, multi-stage, multi-product environment. The existence of coproducts and the combined make-to-order and maketo stock (MTO-MTS) production planning strategy are the main features incorporated.

Working according to a MTO process while the supplier works with a MTS process problem is discussed by Guillaume et al. [43]. They propose a method based on fuzzy modeling allowing a customer to choose a plan taking into account the uncertainty on his requirements when he works in MTO-ATO while his supplier is in MTS.

Based on the above literature review, it is clear that there has been a lot of research done in the areas of MTS/MTO planning and supplier selection and a few papers combining them. It is noted that few papers deal with integrated production - inventory problems along with MTS/MTO production strategy and these papers concern with minimizing the inventory holding cost only So the objective of the paper is to integrate the supplier selection problem along with the inventory, production and distribution problems across the various stages of the supply chain under MTS/MTO strategy as a single mathematical model aiming to minimize the total cost, maximize the facility utilization, and minimize total delivery time. This paper is a first step in this direction.

\section{Model Formulation}

Although the importance of a hybrid MTS/MTO strategy which combines the advantages of MTS and MTO strategies, the researchers focus on the decoupling point and which product will the firm decide to produce according to MTS or MTO strategy and few of them study this strategy with aggregate production planning.

\section{2-1- Case study description}

The case study considered here consists of a spinning plant which produces four items; two of them produced under MTS strategy and the other two items under MTO strategy, with a limited capacity over time, three distribution centers which receive, distribute finished products and store excess production. The manufactured products are directly delivered to distribution centers (DCs).The firm owns the manufacturing plant and DCs. Therefore, the manufacturers are responsible for the sales of their products in DCs outlets. The raw material here is cotton which is supplied by a number of suppliers. The raw material passes throw seven manufacturing stages to obtain the finished product.
In this paper, a supplier selection along with an integrated production, inventory and distribution model under MTS/MTO strategy was investigated using FGP approach. The objective is to minimize the total cost, maximize the facility utilization, and minimize the total delivery time of the SC. Lingo 11 is used to obtain the optimum solution.

\section{2-2- Model Assumptions}

The followings are the underlying assumptions for each stage that needs to be stated before we proceed with the model formulation.

\section{2-2-1- Suppliers:}

- Every chosen supplier has a particular minimum shipment quantity that he supplies and maximum order capacity over which he cannot supply for each type of raw material.

- Only one supplier is finally selected in every time period.

\section{2-2-2- Manufacturers:}

- Manufacturing site follows MTS/ MTO production strategy.

- For MTO production strategy the manufacturing process is instantaneous, i.e., the plant can produce and ship immediately when the order arrives without any time delay.

- Backorders are not considered in this stage .

- The plant has a capacity limit for producing finished products.

- The plant has a limited capacity for storing finished products.

- The plant has a limited capacity for storing raw material.

- $\quad$ For MTS products there is safety stock inventory in each time period.

- Inventory in any period $t$ represents the inventory level at end of the time period $t$.

- Initial inventories are assigned.

- Set up cost is not considered because it is very small and accure at one stage only (spinning stage.)

- Unit transportation cost of finished products from the plant to $\mathrm{DC} \mathrm{k}$ is independent on the type of finished product. 


\section{2-2-3- Distribution centers:}

- Inventory in any period $t$ is the inventory level at end of the time period $t$.

- Initial inventories are assigned to each DC.

- Backorders are not allowed for MTO products.

- Each DC has a limited storage capacity for finished products.

- Unit holding cost for finished products is independent on the type of the finished product at $\mathrm{DC} \mathrm{k}$.

\subsection{Integrated production, inventory, and} distribution model under MTS/MTO strategy.

Here the problem consisted of one supplier, one plant, and three distribution centers. Our objective is to minimize the total cost for the supply chain.

\subsubsection{Definitions of Symbols}

\begin{tabular}{|c|c|c|}
\hline $\mathrm{Z}$ & Set of suppliers $(1,2,3 \ldots \ldots Z)$. & 2.00 \\
\hline $\mathrm{X}_{\mathrm{s}}$ & $\begin{array}{l}\text { Set of products based upon MTS } \\
\text { strategy }\left(1,2,3, X_{S}\right)\end{array}$ & $\mathrm{PI}_{\mathrm{xs} 0}$ \\
\hline $\mathrm{x}_{\mathrm{o}}$ & $\begin{array}{l}\text { Set of products based upon MTO } \\
\text { strategy }\left(1,2,3, X_{O}\right)\end{array}$ & D I $\mathrm{xskt}_{\mathrm{n}}$ \\
\hline $\mathrm{k}$ & Set of distribution centers $(1,2, . . \mathrm{K})$ & $\mathrm{D} \mathrm{I}_{\mathrm{xsk} 0}$ \\
\hline $\mathrm{t}$ & Time period index $(\mathrm{t}=1,2,3 \ldots \mathrm{T})$ & \\
\hline QPL & $\begin{array}{l}\text { Quality standard set by the } \\
\text { manufacturer for raw material }\end{array}$ & $\mathrm{DIO}_{\text {xokt }}$ \\
\hline QSUPzt & $\begin{array}{l}\text { Quality of raw material from } \\
\text { supplier } \mathrm{z} \text { in time period } \mathrm{t} .\end{array}$ & $\mathrm{DIO}_{\text {xok0 }}$ \\
\hline \multirow[t]{2}{*}{ Rzt } & $\begin{array}{l}\text { The quantity of raw material } \\
\text { shipped from supplier } \mathrm{z} \text { to the }\end{array}$ & $\mathrm{F}$ \\
\hline & Plant in time period $t$ & FO \\
\hline $\mathrm{Vt}$ & $\begin{array}{l}\text { Quantity of raw material reaching } \\
\text { the plant from the selected } \\
\text { supplier } \mathrm{z} \text { in time period } \mathrm{t} \text {. }\end{array}$ & Yzt \\
\hline Maxsup & $\begin{array}{l}\text { The maximum capacity of the sup- } \\
\text { plier for raw material. }\end{array}$ & $\mathrm{Bkt}$ \\
\hline Minsup & $\begin{array}{l}\text { Minimum quantity supplied by the } \\
\text { supplier for raw material. }\end{array}$ & $\mathrm{CBk}$ \\
\hline $\operatorname{CSUP}_{\mathrm{t}}$ & $\begin{array}{l}\text { The unit transportation and purch- } \\
\text { asing cost for raw material from } \\
\text { the supplier to the plant in period } \\
\mathrm{t}\end{array}$ & Vkt \\
\hline $\mathrm{D}$ & Available capacity of the plant. & \\
\hline $\mathrm{Cs}_{\mathrm{xs}}$ & $\begin{array}{l}\text { Unit processing cost of product S } \\
\text { produced under MTS Strategy. }\end{array}$ & NS \\
\hline $\mathrm{Co}_{\mathrm{xo}}$ & $\begin{array}{l}\text { Unit processing cost of product O } \\
\text { produced under MTO strategy. }\end{array}$ & NO \\
\hline $\mathrm{Cd}_{\mathrm{k}}$ & $\begin{array}{l}\text { Unit transportation cost of } \\
\text { products }(\mathrm{S} \text { and } \mathrm{O}) \text { from the plant } \\
\text { to } \mathrm{DC}_{\mathrm{k}}\end{array}$ & \\
\hline HR & $\begin{array}{l}\text { Unit holding cost per period for } \\
\text { raw material. }\end{array}$ & \\
\hline $\mathrm{HS}_{\mathrm{xs}}$ & Unit holding cost per period for & \\
\hline
\end{tabular}

item $S$ at the plant.

$\mathrm{Hd}$

$\mathrm{W}_{\mathrm{R}}$

$\mathrm{W}_{\mathrm{S}}$

$\mathrm{Wd}_{\mathrm{k}}$

$\mathrm{S}_{\mathrm{xst}}$

$\mathrm{O}_{\mathrm{xot}}$

$\mathrm{Q}_{\mathrm{xskt}}$

$\mathrm{QO}_{\text {oxkt }}$

$\mathrm{IR}_{\mathrm{t}}$

$\mathrm{IR}_{0}$

$\mathrm{PI}_{\mathrm{xst}}$

$\mathrm{I}_{\mathrm{xs} 0}$

$I_{\text {xskt }}$

$\mathrm{I}_{\mathrm{xsk} 0}$

$\mathrm{IO}_{\text {xokt }}$

$\mathrm{IO}_{\text {xok0 }}$

kt

CBk

t

Unit holding cost per period for item(S and O) at DCs k.

Storage capacity for row material at the plant.

Storage capacity for item $\mathrm{S}$ at the plant.

Storage capacity at DC k.

Amount of item $\mathrm{S}$ produced in period $t$.

Amount of item $\mathrm{O}$ produced in period t.

Amount of item $\mathrm{S}$ delivered from the plant to DCs $\mathrm{k}$ in period $t$.

Amount of item $\mathrm{O}$ delivered from the plant to DCs $\mathrm{k}$ in period t.

Inventory level for raw material at the plant in period $t$.

Initial Inventory level for raw material at the plant.

Inventory level for item $\mathrm{S}$ at the plant in period $t$.

Initial Inventory level for item $\mathrm{S}$ at the plant.

Inventory level for item S at DCs $\mathrm{k}$ in period $\mathrm{t}$.

Initial Inventory level for item $\mathrm{S}$ at DCs k.

Inventory level for item $\mathrm{O}$ at

DCs $\mathrm{k}$ in period $\mathrm{t}$.

Initial Inventory level for item $\mathrm{O}$ at DCs k.

Demand for item S at DCs outlet $\mathrm{k}$ in period $\mathrm{t}$

Demand for item O at DCs

outlet $\mathrm{k}$ in period $\mathrm{t}$

Binary variable denoting

whether supplier $\mathrm{Z}$ is selected

time period $t$ for raw material.

Backorders at DCS $\mathrm{k}$ at the end

of time period $t$

Backorders cost at DCS k

Delivery time per unit for $\left(\mathrm{X}_{\mathrm{S}}\right.$ or

$\mathrm{X}_{\mathrm{O}}$ ) product from the plant to

$\mathrm{DC}_{\mathrm{S}} \mathrm{k}$ in period $\mathrm{t}$ our/unit

Capacity per truck delivered for

$\left(\mathrm{X}_{\mathrm{S}}\right.$ or $\left.\mathrm{X}_{\mathrm{O}}\right)$ from the plant to

$\mathrm{DC}_{\mathrm{S}} \mathrm{k}$ in period $\mathrm{t}$.

Unit processing time of item $\mathrm{S}$.

Unit processing time of item $\mathrm{O}$. 


\subsubsection{Model Formulation}

The three objective functions are formulated as follows:-

\section{Minimize the total cost}

Min total cost $=$ purchasing cost + production cost + inventory cost from suppliers to factory and factory to DCs + transportation cost for product from factory to $\mathrm{DCs}$

$$
\begin{aligned}
& \operatorname{Min}=\sum_{z t} \operatorname{CSUP} \boldsymbol{P}_{z t}^{*} R+\sum_{x s t} \underset{x s}{C S} *{\underset{x s t}{S}+}_{x o t} \operatorname{CO}_{x o} * \underset{x o t}{O+} \\
& \sum_{t} H R * I_{t}+\sum_{x s t} H S_{x s}^{*} \underset{x s t}{P I}+\sum_{k} H_{k} d * \\
& \left(\sum_{x s k t} D I+\sum_{x s t} D I O\right)+\sum_{k} C_{k} d^{*}\left(\sum_{x s k t \text { xskt }} Q+\sum_{x o k t} \underset{x o k t}{Q O}\right)
\end{aligned}
$$

\section{Maximize the Utilization Level of Facilities}

Capacity utilization can be measured in percentage of actual output or in the percentage of time a constrained resource is used. This study uses timebased measurement. The facilities utilization can be calculated as

$$
\begin{aligned}
& \text { MaxWt }= \\
& \sum_{X S} \sum_{t} N_{x S} S * \underset{x s t}{S / D}+\sum_{X O} \sum_{t} N_{x O} O * \underset{x o t}{O / D}
\end{aligned}
$$

\section{Minimization of Total Delivery Time}

$$
\begin{aligned}
& \text { Min F3 }= \\
& \sum_{x s} \sum_{k} \sum_{t} \frac{{ }_{k t}^{U+N S} * \underset{x s k t}{Q}+}{\sum_{x t}}+ \\
& \sum_{k} \sum_{t} \frac{\bigcup_{k t}+N O}{V} * \underset{k o k t}{Q}
\end{aligned}
$$

\subsection{Model Constraints}

\subsubsection{Raw Material Constraints}

The supplier selection model is formulated based on the following preferences of the buyer.

The quality of raw material purchased QSUPzt must meet the specific standard set for that material by the manufacturer QPL for every supplier Z in each time period t:

$\mathrm{QSUP}_{\mathrm{zt}} \geq \mathrm{QPL}^{*} \mathrm{Y}_{\mathrm{zt}} \quad \forall \mathrm{z}, \mathrm{t}$

The capacity of the supplier for raw material must be high enough to meet the quantity of raw material ordered from the supplier in each time period $\mathrm{t}$ :

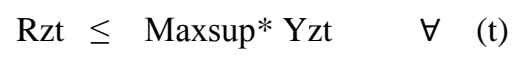

The order quantity of raw material must meet the minimum purchase requirement of supplier in every time period $\mathrm{t}$ :

$\mathrm{R}_{\mathrm{zt}} \geq$ Minsup $^{*} \mathrm{Y}_{\mathrm{zt}} \quad \forall \quad(\mathrm{t})$

The quantity of raw material that reached to the plant must meet the quantity of raw material needed for producing all types of products in every time period.

$$
V \geq\left(\sum_{x s t} S_{x s t}+\sum_{x o t} O\right) \quad \forall \mathrm{x}_{\mathrm{s}}, \mathrm{x}_{\mathrm{o}}, \mathrm{t}
$$

For every time period t, only one supplier is finally selected.

$$
\sum_{z} Y=1 \quad \forall(\mathrm{t})
$$

\subsubsection{PLANT CONSTRAINTS}

The quantity of raw material reaching the plant $\mathrm{Vt}$ from the selected supplier $\mathrm{z}$ equal to the quantity of raw material shipped from that supplier Rzt to the plant in time period $t$.

$V=\sum_{z t} R_{z t} \quad \forall \mathrm{z}, \mathrm{t}$

The constraint (3.9) assures the linearity of the following constraint.

The quantity of raw material which used to produce any product $(\mathrm{S}$ or $\mathrm{O}$ ) in any period cannot exceed the inventory of raw material in that period.

$$
\underset{(t-1)}{I R}+V_{t}-\left(\sum_{x s t} S_{x s t}+\sum_{x o t} O\right) \leq \underset{t}{I R t} \quad \forall \mathrm{x}_{\mathrm{s}}, \mathrm{x}_{\mathrm{o}}, \mathrm{t}
$$

The inventory of raw material stored at the plant must be within the storage capacity limits for each time period $t$ :
$\mathrm{IR}_{\mathrm{t}} \leq \mathrm{WR}$
$\forall \quad(\mathrm{t})$

For MTS products, the inventory of the products in any period must exceed the demand for each time period $\mathrm{t}$ :

$$
\underset{x s(t-1)}{P I}+\underset{x s t}{S}-\sum_{k} \underset{x s k t}{Q} \leq \underset{x s t}{P I} \quad \forall \mathrm{x}_{\mathrm{s}}, \mathrm{t}
$$

The inventory of MTS products stored at the plant must be within the storage capacity limits of the products for each time period $\mathrm{t}$ :

$\sum_{x s} \underset{x s k t}{P I} \leq W P \quad \forall \quad(\mathrm{t})$

The inventory of MTS products should exceed the safety stock value.

$\mathrm{PI}_{\mathrm{xst}} \geq \mathrm{SSV} \quad \forall(\mathrm{t})$ 
For MTO products, the quantity produced of these products equal its demand.

$$
\underset{x o t}{O}=\sum_{K} \underset{x o t}{Q O} \quad \forall \quad \mathrm{x}_{0}, \mathrm{t}
$$

The quantity of all products produced at any time period must not exceed the production capacity.

$$
\sum_{x s} \underset{x s t}{S * N S} \sum_{+x o} \underset{x O t}{O * N O \leq D} \forall(\mathrm{t})
$$

\subsubsection{DISTRIBUTION CENTERS CONSTRAINTS}

The actual demand for MTS items at DCs outlet in any period cannot exceed the forecasted demand in that period

$$
\mathrm{DI}_{\mathrm{xs}(\mathrm{t}-1)}+\sum_{k} \bigotimes_{x \mathrm{~s} k \mathrm{kt}}-\mathrm{DI}_{\mathrm{xst}} \geq \underset{\forall \mathrm{x}_{\mathrm{s}}, \mathrm{k}, \mathrm{t}}{\mathrm{F}}
$$

Backorders are allowed for MTS items only.

$$
\begin{aligned}
& \text { At } \mathrm{t} \geq 2 \\
& \mathrm{DI}_{\mathrm{xsk}(\mathrm{t}-1)}+\sum_{k} \underset{x, s k t}{\boldsymbol{Q}}-\mathrm{DI}_{\mathrm{xst}}-\mathrm{B}_{\mathrm{xsk}(\mathrm{t}-1)}+\mathrm{B}_{\mathrm{xskt}} \geq \mathrm{F} \\
& \forall \mathrm{xs}, \mathrm{k}, \mathrm{t} \quad \text { (2.18) }
\end{aligned}
$$

For MTO items, the following constraint presents the inventory balance at the $\mathrm{DC}_{\mathrm{s}}$ outlet.

$$
\underset{x o(t-1)}{D I O}+\sum_{k} \underset{x o k t}{Q O}-\underset{x o t}{D I O}=F O \quad \forall \mathrm{x}_{\mathrm{o}}, \mathrm{k}, \mathrm{t}
$$

the DCs must be within the storage capacity limits for each time period $t$ :

$\sum_{x s} D_{x s k t} I+\sum_{x o} \underset{x o k t}{D I O} \leq \underset{k}{W d} \quad \forall \mathrm{k}, \mathrm{t}$

The restrictions of non-negativity on the decision variables.

$\mathrm{S}_{\mathrm{xst}} \geq 0, \mathrm{O}_{\mathrm{xot}} \geq 0, \mathrm{Q}_{\mathrm{xskt}} \geq 0, \mathrm{QO}_{\mathrm{xokt}} \geq 0, \mathrm{IR}_{\mathrm{t}} \geq 0$,

$$
\mathrm{PI}_{\mathrm{xst}} \geq 0, \mathrm{DI}_{\mathrm{xskt}} \geq 0, \mathrm{DIO}_{\text {xokt }} \geq 0
$$

\section{Model Implementation and Analysis}

The model formulated earlier is tested for a set of realistic data and the results are discussed.

$\mathrm{Cd} 1=50 \mathrm{LE} / \mathrm{Ton}, \mathrm{Cd} 2=75 \mathrm{LE} / \mathrm{Ton}$,

$\mathrm{Cd} 3=100 \mathrm{LE} / \mathrm{Ton}$.

Quality Standard set $=4$. If the quality of raw material is bigger than or equal this value, the raw material is good quality. Otherwise it is fair.

\section{Given Data}

Number of suppliers, $Z=3$

Number of $\mathrm{DC}_{\mathrm{s}}, \mathrm{k}=3$

Number of time periods, $\mathrm{t}=6(\mathrm{t}=1,2,3, . ., 6)$

Table (3-1) summarizes the data for the raw materials and suppliers. Values for quality are based on a rating scale (1-Fair to 10-Excellant) such that high values represent better quality. Table 3-2 contains plant data and Table 3-3 includes the data for the $\mathrm{DC}_{\mathrm{s}}$ items.

3-1-1- Raw materials and Suppliers data

Table 3-1: Raw materials and Suppliers data

\begin{tabular}{|c|c|c|c|}
\hline & $\begin{array}{c}\text { Supplier } \\
\mathbf{3}\end{array}$ & $\begin{array}{c}\text { Supplier } \\
\mathbf{2}\end{array}$ & $\begin{array}{c}\text { Supplier } \\
1\end{array}$ \\
\hline $\begin{array}{c}\text { Quality } \\
\text { provided for 6 } \\
\text { time periods }\end{array}$ & $4,1,9,2,1,7$ & $\mathbf{2 , 4 , 6 , 7 , 3 ,}$ & $\mathbf{7 , 9 , 4 , 1 , 9 ,}$ \\
\hline Maximum & & 4 & 4 \\
capacity (ton) & 775 & 650 & 670 \\
\hline Minimum order & & & \\
quantity (ton) & 60 & 65 & 50 \\
\hline & 8600 & $\mathbf{8 6 0 0}$ & $\mathbf{8 3 0 0}$ \\
& $\mathbf{8 7 0 0}$ & $\mathbf{8 4 0 0}$ & $\mathbf{8 4 0 0}$ \\
Cost per unit & $\mathbf{8 8 0 0}$ & $\mathbf{8 6 0 0}$ & $\mathbf{8 1 0 0}$ \\
for 6 time & $\mathbf{8 5 0 0}$ & $\mathbf{8 7 5 0}$ & $\mathbf{8 2 0 0}$ \\
periods & $\mathbf{8 5 0 0}$ & $\mathbf{8 4 0 0}$ & $\mathbf{8 3 0 0}$ \\
(LE/ton) & $\mathbf{8 7 0 0}$ & $\mathbf{8 6 0 0}$ & $\mathbf{8 1 5 0}$ \\
& & & \\
\hline
\end{tabular}

\section{3-1-2- Plant data}

Production capacity (Tons) ,D = 100Ton

Production cost for MTS products, $\mathrm{C}_{\mathrm{Sxs}}=5000$

LE/Ton, 4000 LE /Ton

Production cost for MTO products, $\mathrm{C}_{\mathrm{SXO}}=10832$

LE/Ton, 4880 LE /Ton

Raw material initial inventory, IR0 $=50$ Ton

Raw material storage capacity, WR $=60$ Ton

MTS products storage capacity, WS $=15$ Ton

MTS products inventory holding cost per unit time period, HSxs = 140LE/Ton, $120 \mathrm{LE} /$ Ton

Raw material inventory holding cost per unit time period, HR = $130 \mathrm{LE} / \mathrm{Ton}$

Safety stock value, $\mathrm{SSV}=1$ Ton

For simplicity, we assume that the unit transportation cost of the finished products from the plant to the DCs is independent of the product type. 
M. S. Abass, A.M. Gaafer, A. R. Saad "MODELING AND ANALYSIS OF A T ..."

3-1-3- $\mathrm{DC}_{\mathrm{s}}$ data

Table 3-2: DCs Demand data

\begin{tabular}{|c|c|c|c|c|c|c|c|c|c|c|c|c|}
\hline \multirow{4}{*}{ Time period } & \multicolumn{12}{|c|}{ Customer's demand at the $\mathrm{DC}_{\mathrm{s}}$ (Ton) } \\
\hline & \multicolumn{4}{|c|}{ DC 1} & \multicolumn{4}{|c|}{ DC 2 } & \multicolumn{4}{|c|}{ DC 3 } \\
\hline & \multicolumn{2}{|c|}{ MTS } & \multicolumn{2}{|c|}{ MTO } & \multicolumn{2}{|c|}{ MTS } & \multicolumn{2}{|c|}{ MTO } & \multicolumn{2}{|c|}{ MTS } & \multicolumn{2}{|c|}{ MTO } \\
\hline & S1 & S2 & 01 & $\mathbf{O 2}$ & S1 & $\mathbf{S 2}$ & 01 & O2 & S1 & $\mathbf{S 2}$ & 01 & $\mathbf{O 2}$ \\
\hline 1 & 7 & 20 & 5 & 15 & 4 & 15 & 6 & 10 & 4 & 20 & 7 & 12 \\
\hline 2 & 10 & 9 & 10 & 3 & 14 & 10 & 8 & 3 & 10 & 11 & 10 & 5 \\
\hline 3 & 7 & 8 & 6 & 2 & 7 & 11 & 10 & 2 & 5 & 13 & 8 & 2 \\
\hline 4 & 6 & 7 & 15 & 0 & 6 & 4 & 7 & $\mathbf{0}$ & 7 & 2 & 11 & 0 \\
\hline 5 & 1 & 2 & 5 & 0 & 1 & 3 & 5 & 0.5 & 1 & 2 & 4 & 0 \\
\hline 6 & 9 & 8 & 2 & 5 & 6 & 7 & 2 & 4 & 9 & 8 & 2 & 5 \\
\hline
\end{tabular}

Table 3-3: DCs data

\begin{tabular}{|c|c|c|c|c|c|c|c|c|c|c|c|c|}
\hline & \multicolumn{4}{|c|}{ DC1 } & \multicolumn{4}{|c|}{ DC2 } & \multicolumn{4}{|c|}{ DC3 } \\
\hline & \multicolumn{2}{|c|}{ MTS } & \multicolumn{2}{|c|}{ MTO } & \multicolumn{2}{|c|}{ MTS } & \multicolumn{2}{|c|}{ MTO } & \multicolumn{2}{|c|}{ MTS } & \multicolumn{2}{|c|}{ MTO } \\
\hline & S1 & $\mathbf{S 2}$ & O1 & $\mathrm{O2}$ & S1 & S2 & O1 & $\mathbf{O 2}$ & S1 & S2 & 01 & $\mathbf{O 2}$ \\
\hline Initial inventory, $\mathrm{DI}_{(\mathrm{xs} \text { or xo) } 0}$ & 10 & 25 & 0 & $\mathbf{0}$ & 8 & 20 & 0 & $\mathbf{0}$ & 20 & 30 & $\mathbf{0}$ & 0 \\
\hline Maximum inventory capacity, & \multicolumn{4}{|c|}{50 Ton } & \multicolumn{4}{|c|}{40 Ton } & \multicolumn{4}{|c|}{30 Ton } \\
\hline $\begin{array}{l}\text { Inventory holding cost per unit time } \\
\text { period, }\end{array}$ & \multicolumn{4}{|c|}{$140 \mathrm{LE}$} & \multicolumn{4}{|c|}{$150 \mathrm{LE}$} & \multicolumn{4}{|c|}{$130 \mathrm{LE}$} \\
\hline
\end{tabular}

\subsection{Results}

\subsubsection{Results}

The optimization software, LINGO is used to generate the fuzzy goal linear program and solve it.

Table 3-4: Supplier selection, Order quantity, and raw material inventory

\begin{tabular}{|c|c|c|c|}
\hline $\begin{array}{c}\text { Time } \\
\text { period }\end{array}$ & $\begin{array}{c}\text { Supplier } \\
\text { selected }\end{array}$ & $\begin{array}{c}\text { Quantity } \\
\text { ordered }\end{array}$ & inventory \\
\hline $\begin{array}{c}\text { Time } \\
\text { period } \\
1\end{array}$ & 1 & 63 & 50 \\
\hline $\begin{array}{c}\text { Time } \\
\text { period } \\
2\end{array}$ & 1 & 50 & 50 \\
\hline $\begin{array}{c}\text { Time } \\
\text { period } \\
3\end{array}$ & 1 & 50 & 50 \\
\hline $\begin{array}{c}\text { Time } \\
\text { period } \\
4\end{array}$ & 2 & $\underline{65}$ & 50 \\
\hline $\begin{array}{c}\text { Time } \\
\text { period } \\
5\end{array}$ & 1 & 50 & $\underline{53}$ \\
\hline $\begin{array}{c}\text { Time } \\
\text { period } \\
6\end{array}$ & 1 & 50 & 60 \\
\hline
\end{tabular}

It is clear from Fig. (3-4) that the first supplier is selected for most of the time periods and the ordered quantity for each time period covers the production quantity needed for produce all items. Another interesting observation is that the quantities ordered for all periods are equal to the raw material minimum order quantity values. Also, it is to be noted that there is inventory stored during all time periods and the stored quantity at the end period is equal to the maximum storage capacity for raw material. Fig. (3-1).

From Figs.(3-2),(3-3), It can be seen that the plant produce hybrid products (MTS-MTO products) all over the time periods and the sum of the quantity of the fourth products is less than the plant capacity for each time period. Another notation that there is no production of the first MTS item at the first, the second, the third and the last time periods. The reason for this for the first and the last periods is due to the shipment quantity since there is no shipment quantity from the plant to all $\mathrm{DC}_{\mathrm{s}}$ at these time periods, but for the second and the third periods there is a shipment quantity from the plant to the first DC which covered by the inventory stored at this period. The reason for this is the initial inventory stored at the $\mathrm{DC}_{\mathrm{s}}$ at the start of the time horizon beside the backorder quantity is 
shipped immediately during this time periods to satisfy the demands. It can also be seen that there is no production of MTO second item at the fourth period because there is no demands for this item from all the three $\mathrm{DC}_{\mathrm{s}}$ at that period.

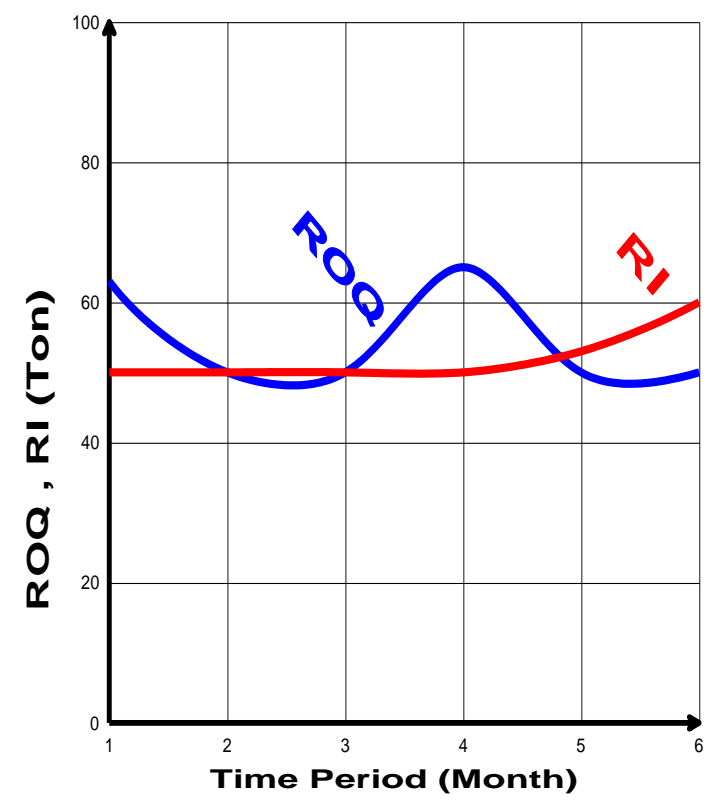

Fig.(3-1) Order quantity, and raw material inventory.

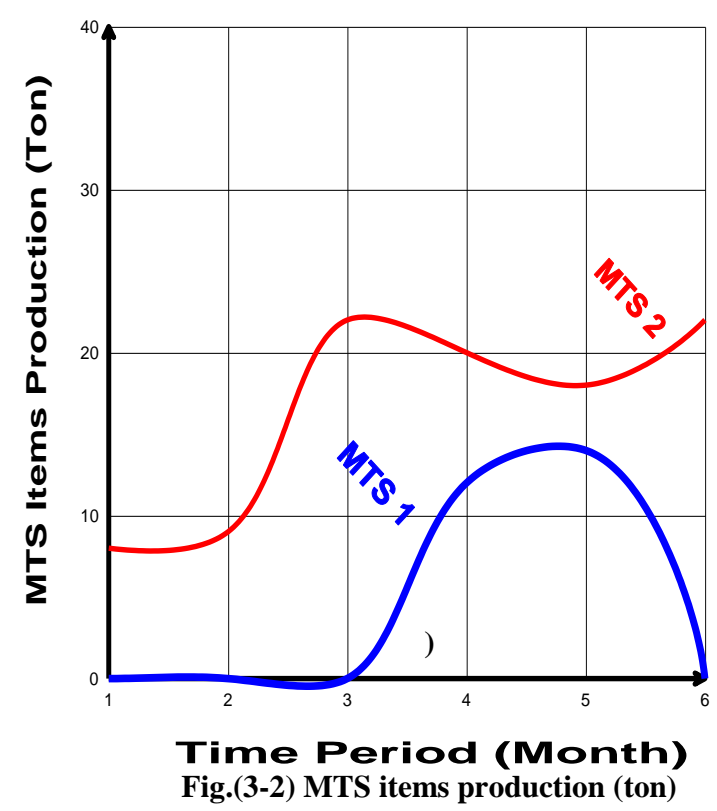

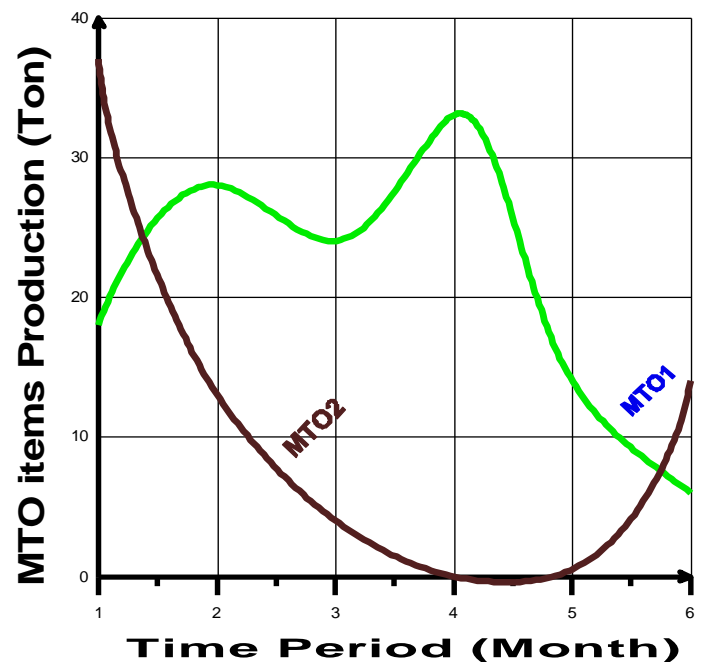

Fig.(3-3) MTO items production (ton)

It is clear that the inventory for the two products for all time periods is equal to the safety stock value SSV except for the first MTS item at the first and the second time periods. This is because there is no shipment quantity from the plant to any of the $\mathrm{DC}_{\mathrm{s}}$ at the first period so the stored inventory remains unchanged. But at the second period there is a shipment quantity from the plant to the first DC which is less than the stored inventory at this period as shown in Fig.(3-4).

Fig. (3-5) indicated that the zero shipment MTS products quantity from the plant to the $\mathrm{DC} 1$ at the first, fourth, and sixth periods is due to the inventory stored and the backorder quantity at these periods which cover the demand at this DC outlet. On the other hand there is a shipment MTO items quantity for each time period except for the second MTO item at the third and fifth periods that is because there is no demand at these periods Fig.(3-6).

Figs.(3-7) and (3-8) illustrated that there are zero shipment quantities for MTS first item for the first three and the last periods and for the second MTS item at the first and the third periods at this DC. So, a same explanation can be used for zero shipment quantity. While there is a shipment quantity for MTO items for each time period except for the second MTO item at the fourth period. So, a same explanation can be used for this zero shipment quantity also. 


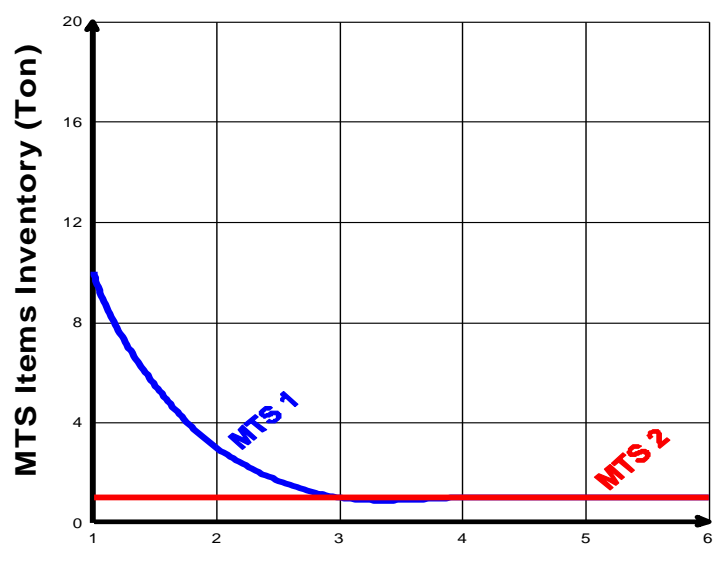

Time Period (Month)

Fig.(3-4) MTS products inventory quantity

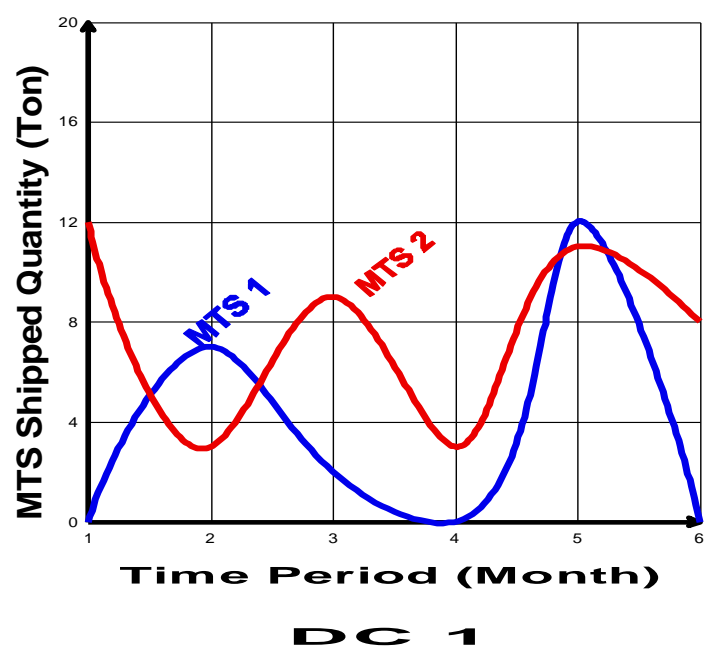

Fig.(3-5) Finished MTS products quantity transported from the plant to DC1

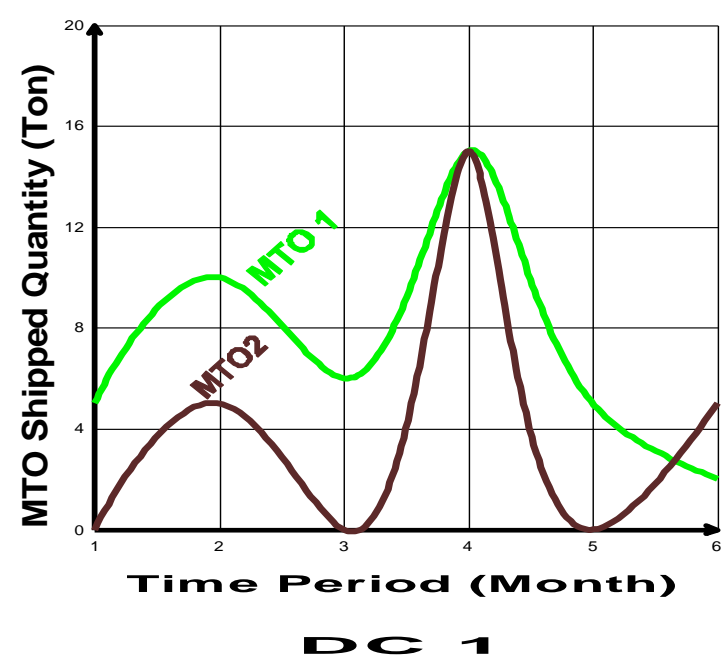

Fig.(3-6) Finished MTo products quantity transported from the plant to DC1

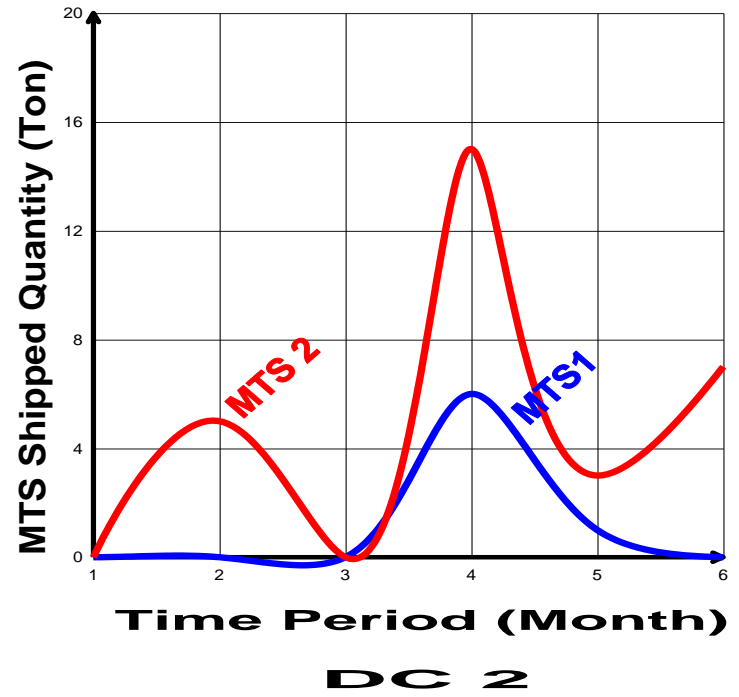

Fig.(3-7) Finished MTS products quantity transported from the plant to $\mathrm{DC} 2$

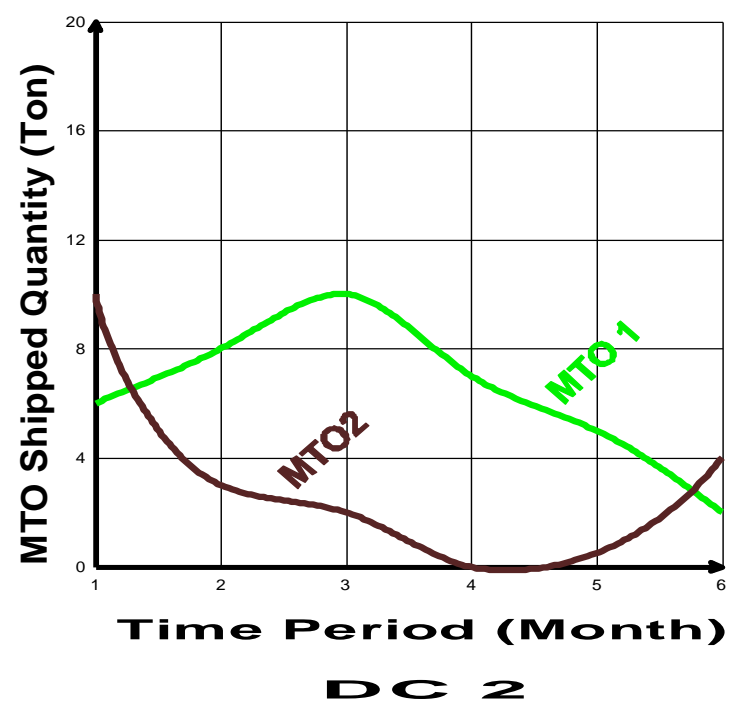

Fig.(3-8) Finished MTO products quantity transported from the plant to DC2

It can be seen from Figs.(3-9) and (3-10) that there are shipment quantities for both MTS and MTO items for all periods except some periods science there are no shipment quantities. The same explanation can be used for zero shipment quantities.

From table (3-5) it can be seen that for MTO products there is no inventory at all time horizon for the three $\mathrm{DC}_{\mathrm{s}}$ and this agreed with their production strategy. For MTS products there is inventory at the first period for some items and extended to the third period for another items this is due to the inventory and backorder quantity as explained before but for the remaining periods its zero and that's to minimize the cost of holding inventory aiming to make the inventory at the plant this is from 
one view point. From the other view point, the actual demand may be less than or equal the expected demand and this will result in inventory at the $\mathrm{DC}_{\mathrm{s}}$.

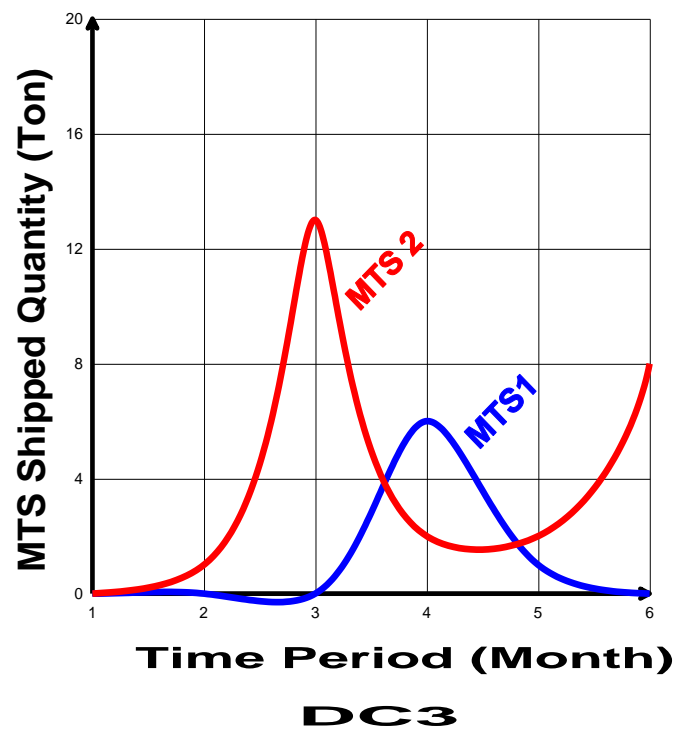

Fig.(3-9) Finished MTS products quantity transported from the plant to DC3

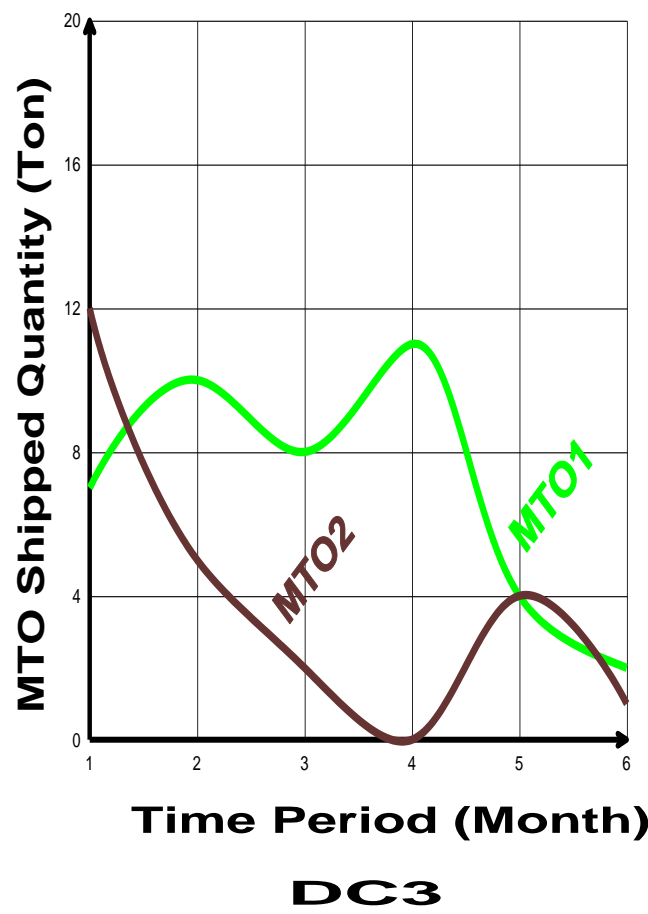

Fig.(3-10) Finished MTO products quantity transported from the plant to DC3

Table(3-5) DCs inventory quantity

\begin{tabular}{|c|c|c|c|c|c|c|c|c|c|c|c|c|}
\hline \multirow{3}{*}{$\begin{array}{l}\text { Time } \\
\text { Period }\end{array}$} & \multicolumn{4}{|c|}{ DC1 } & \multicolumn{4}{|c|}{ DC2 } & \multicolumn{4}{|c|}{ DC3 } \\
\hline & \multicolumn{2}{|c|}{ MTS } & \multicolumn{2}{|c|}{ MTO } & \multicolumn{2}{|c|}{ MTS } & \multicolumn{2}{|c|}{ MTO } & \multicolumn{2}{|c|}{ MTS } & \multicolumn{2}{|c|}{ MTO } \\
\hline & DI11 & DI21 & DIO11 & DIO21 & DI12 & DI22 & DIO12 & DIO22 & DI13 & DI23 & DIO13 & DIO23 \\
\hline $\begin{array}{l}\text { Time } \\
\text { Period1 }\end{array}$ & 3 & $\mathbf{0}$ & 0 & 0 & 21 & 5 & $\mathbf{0}$ & $\mathbf{0}$ & 16 & 10 & $\mathbf{0}$ & $\mathbf{0}$ \\
\hline $\begin{array}{c}\text { Time } \\
\text { Period2 }\end{array}$ & 0 & 0 & $\mathbf{0}$ & $\mathbf{0}$ & 7 & 0 & 0 & $\mathbf{0}$ & 6 & $\mathbf{0}$ & 0 & $\mathbf{0}$ \\
\hline $\begin{array}{c}\text { Time } \\
\text { Period3 }\end{array}$ & 0 & $\mathbf{0}$ & $\mathbf{0}$ & $\mathbf{0}$ & $\mathbf{0}$ & 0 & $\mathbf{0}$ & $\mathbf{0}$ & 1 & $\mathbf{0}$ & $\mathbf{0}$ & $\mathbf{0}$ \\
\hline $\begin{array}{c}\text { Time } \\
\text { Period4 }\end{array}$ & 0 & 0 & 0 & 0 & 0 & 0 & 0 & O & O & $\mathbf{0}$ & O & 0 \\
\hline $\begin{array}{c}\text { Time } \\
\text { Period5 }\end{array}$ & 0 & $\mathbf{0}$ & 0 & $\mathbf{0}$ & $\mathbf{0}$ & 0 & $\mathbf{0}$ & $\mathbf{0}$ & 0 & $\mathbf{0}$ & $\mathbf{0}$ & $\mathbf{0}$ \\
\hline $\begin{array}{c}\text { Time } \\
\text { Period6 }\end{array}$ & $\mathbf{0}$ & $\mathbf{0}$ & $\mathbf{0}$ & $\mathbf{0}$ & $\mathbf{0}$ & $\mathbf{0}$ & $\mathbf{0}$ & $\overline{0}$ & $\overline{0}$ & O & O & $\mathbf{0}$ \\
\hline
\end{tabular}


The following Figs.(3-11), (3-12), and (3-13) illustrates the backorder quantities for all $\mathrm{DC}_{\mathrm{s}}$.

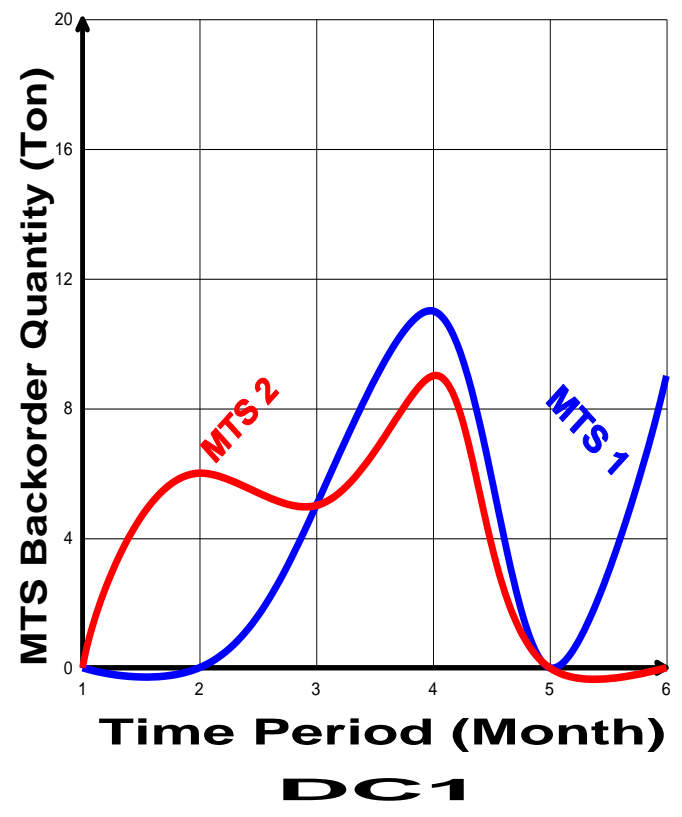

Fig.(3-11) Finished MTS products backorder quantity at DC1

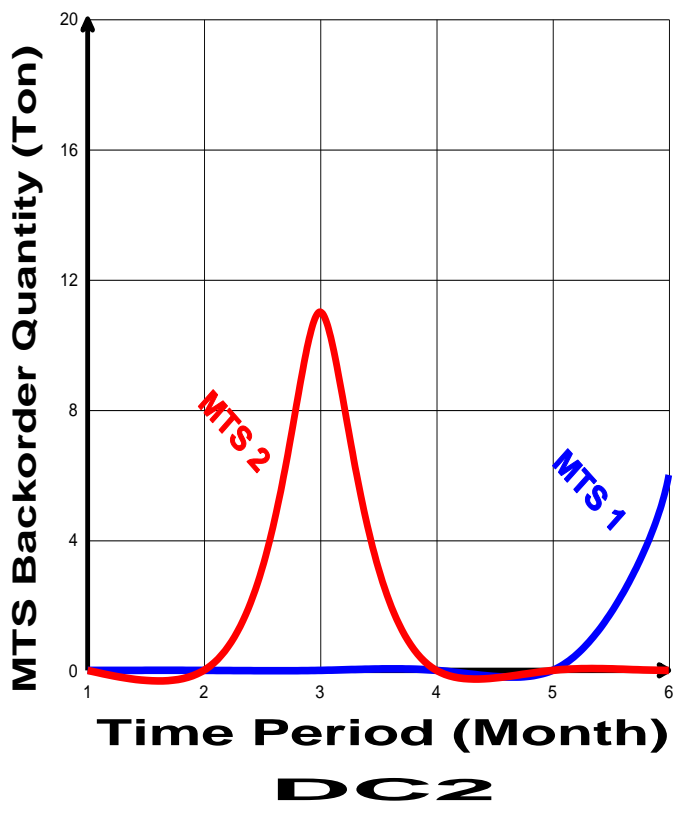

Fig.(3-12) Finished MTS products backorder quantity at DC2

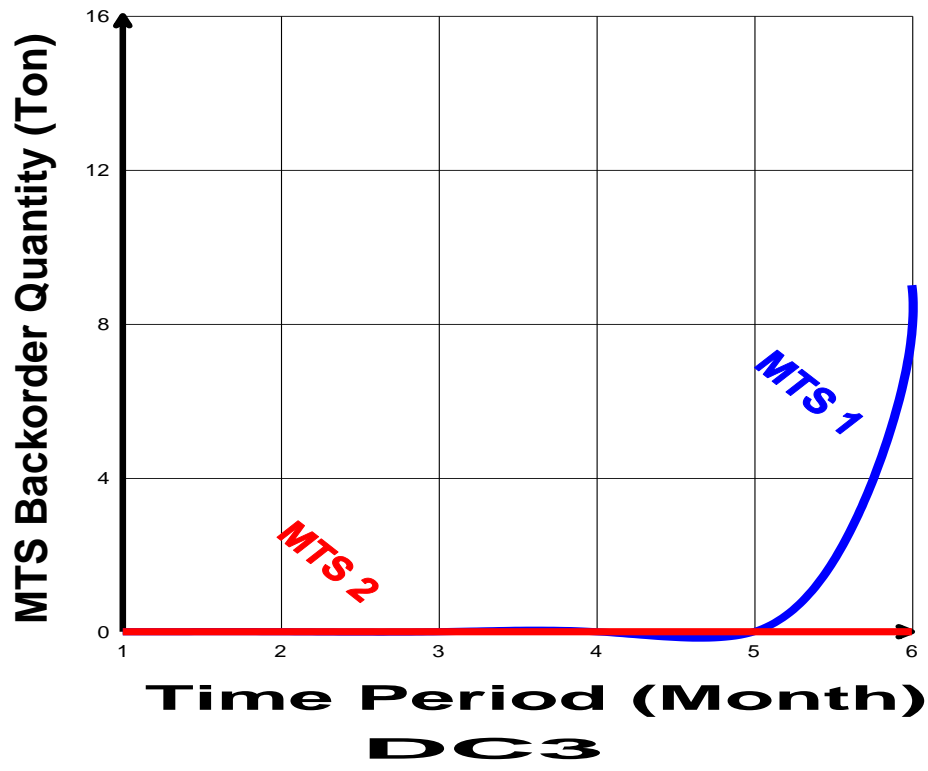

Fig.(3-13) Finished MTS products backorder quantity at DC3 


\section{Concolusion}

Some conclusions and recommendations for further research are discussed.

1. For supplier stage, the supplier was chosen and the optimal raw material shipment quantity has been obtained.

2. For production stage, the optimal production quantities for all products, the inventory levels for raw material and MTS products, and shipment amounts for all products are obtained.

3. For DCs stage, the optimal inventory levels for all products are obtained.

4. The model validated in minimizing total cost and total delivery time and maximizing facility utilization.

\section{References}

[1] Willis H.T., Huston R.C., F. Pohlkamp, "Evaluation measures of just in time supplier performance," Prod. Invent. Manage. J, Vol. 34 (2), pp. 1:5, 1993.

[2] Dickson, G.W, "An analysis of vendor selection systems and decisions," Journal of Purchasing, vol. 2, pp. 5-17, 1966.

[3] Weber, C.A., and Current, J.R, "Vendor selection criteria and methods," European Journal of Operational Research, vol. 50, pp.2-18, 1991.

[4] M Agha Mohammad Ali Kermani, M Nasiri, MH Ali ahmadi, "A Decision-Aid in Supplier Selection for Entrepreneurs, Using Nested-Design, MODM and FAHP. ," International Journal of EEntrepreneurship and Innovation, Vol.1(2), pp.14-29, 2010.

[5] Ali Kokangul, Zeynep Susuz," Integrated analytical hierarch process and mathematical programming to supplier selection problem with quantity discount,"Applied Mathematical Modelling, Vol. 33, pp. 1417-1429, 2009.

[6] Mehtap Dursun, E. Ertugrul Karsak," A QFD-based fuzzy MCDM approach for supplier selection,"Applied Mathematical Modeling, Vol. 37, pp. 5864-5875, 2013.

[7] Hamza Adeinat and José A. Ventura, "Determining the Retailer's
Replenishment Policy Considering Multiple Capacitated Suppliers and Pricesensitive Demand," Proceedings of the 2014 Industrial and Systems Engineering Research Conference Y. Guan and $\mathrm{H}$. Liao, eds.

[8] Abraham Mendoza, José A. Ventura," Analytical models for supplier selection and order quantity allocation," Applied Mathematical Modeling, Vol. 36, pp. 3826-3835, 2012.

[9] Salman Nazari-Shirkouhi, Hamed Shakouri, Babak Javadi, Abbas Keramati," Supplier selection and order allocation problem using a two-phase fuzzy multiobjective linear programming, "Applied Mathematical Modeling, Vol. 37, pp. 9308-9323,2013.

[10]Huseyin Selcuk Kilic," An integrated approach for supplier selection in multi item / multi-supplier environment,"Applied Mathematical Modeling, Vol. 37, pp. 7752-7763, 2013.

[11]Fereshteh Mafakheri, Michele Breton, Ahmed Ghoniem," Supplier selectionorder allocation: A two-stage multiple criteria dynamic programming approach," Int. J. Production Economics, Vol.132, pp. 52-57,2011.

[12]Bein Elahi, Seyed Mohammad SeyedHosseini \& Ahmad Makui,"

[13] A Fuzzy Compromise Programming Solution for Supplier Selection in Quantity Discounts Situation," International Journal of industrial engineering and production research, Vol. 22, pp. 107-114, 2011.

[14]Feyzan Arikan," A fuzzy solution approach for multi objective supplier selection,"Expert Systems with Applications, Vol. 40, pp. 947-952, 2013.

[15]Chin-Nung Liao, Hsing-Pei Kao," Supplier selection model using aguchi loss function, analytical hierarchy process and multi-choice goal programming,"Computers \& Industrial Engineering, Vol. 58, pp. 571-577,2010.

[16] Amy H.I. Lee, He-Yau Kang, Ching-Ter Chang," Fuzzy multiple goal programming applied to TFT-LCD supplier selection by 
downstream manufacturers,"Expert Systems with Applications, Vol. 36, pp. 6318-6325,2009.

[17] Rong-Ho Lin," An integrated FANPMOLP for supplier evaluation and order allocation, "Applied Mathematical Modeling, Vol. 33, pp. 2730-2736, 2009.

[18] Chirawat Woarawichai1, Kritsana Kuruvit1, Paitoon Vashirawongpinyo,"Applying Genetic Algorithms for Inventory Lot-Sizing Problem with Supplier Selection under Storage Capacity Constraints," IJCSI International Journal of Computer Science Issues, Vol. 9, Issue 1, No 1, January 2012.

[19] Aslı Aksoy, Nursel Ozturk," Supplier selection and performance evaluation in just-in-time production environments," Expert Systems with Applications, Vol. 38, pp. 6351-6359,2011.

[20] Amin Amid, S.H.Ghodsypour, Christopher O'Brienc," A weighted additive fuzzy multi objective model for the supplier selection problem under price breaks in a supply Chain," Int. J. Production Economics, Vol.121, pp323332, 2009.

[21] Nima Esfandiari, Mehdi Seifbarghy," Modeling a stochastic multi- objective supplier quota allocation problem with price-dependent ordering,"Applied Mathematical Modeling, Vol. 37, pp. 5790-5800,2013.

[22] R. Mohammad Ebrahim, J. Razmi, H. Haleh," Scatter search algorithm for supplier selection and order lot sizing under multiple price discount environment," Advances in Engineering Software, Vol. 40, pp. 766-776,2009.

[23] Yong Sik Chang, Kyoung Jun Lee," A comparison shopping optimization model based on suppliers' pricing contexts," Expert Systems with Applications, Vol. 37, pp. 5736-5744,2010.

[24] Jan Olhager. "The role of the customer order decoupling point in production and supply chain management.", Computers in Industry,Vol. 61,PP. 863:868,2010.

[25] Jan Olhager, "The Role of Decoupling Points in Value Chain Management, "Springer-Verlag Berlin Heidelberg, 2012.
[26]X.Y. Sun, P. Jib, L.Y. Sun, Y.L. Wang. "Positioning multiple decoupling points in a supply network." Int.J. Production Economics,Vol. 113,PP. 943:956,2008.

[27]H. Shidpour, C. Da Cunha, A. Bernard. "Analyzing single and multiple customer order decoupling point positioning based on customer value: A multi-objective approach.",Procedia CIRP,Vol. 17,PP. 669 : 674,2014.

[28] J. Olhager, "Strategic positioning of order penetration point," Int. J.

[29] Prod. Econ., Vol. 85, pp. 319-329, 2003.

[30]H. Rafiei, M. Rabbani, "An MADM Framework toward Hierarchical Production Planning in Hybrid MTS/MTO Environments,"World cademy of Science, Engineering and Technology, Vol.3, pp.10-25, 2009.

[31] Hamed Rafiei, Masoud Rabbani, "Hybrid MTS/MTO order partitioning framework based upon fuzzy analytic network process," Applied Soft Computing, Vol.19, pp. 312-321, 2014.

[32]Eman Almehdawe, Elizabeth Jewkes, "Performance analysis and optimization of hybrid manufacturing systems under abatch ordering policy, " Int. J. Production Economics, Vol. 144, pp. 200-208, 2013.

[33]Zhe George Zhan, Ilhyung Kim, Mark Springer, Gang shu (George) Cai, Yugang $\mathrm{Yu}$, "Dynamic pooling of make-to-stock and make-to-order operations.", Int. J. Production Economics, Vol. 144, pp.4456, 2013.

[34]H. Rafiei, M. Rabbani, "Order partitioning and Order Penetration Point location in hybrid Make-To-Stock/Make-To-Order," production contexts Computers \& Industrial Engineering, Vol. 61, pp. 550560, 2011.

[35]N. Zaerpour, M. Rabbani, A.H. Gharehgozli, R. Tavakkoli-Moghaddam, "Make-to-order or make-to-stock decision by a novel hybrid approach," Advanced Engineering Informatics, Vol. 22, pp. 186-201, 2008.

[36]Philip Kaminsky and Onur Kaya, "Combined make-to-order/make-to-stock supply chains, " IIE Transactions, Vol. 41, pp. 103-119, 2009. 
[37] Mahdokht Kalantari, Masoud Rabbani, Mahmood Ebadi, "A decision support system for order acceptance/rejection in hybrid MTS/MTO production systems," Applied Mathematical Modelling, Vol. 35, pp. 1363-1377, 2011.

[38] Muh-Cherng Wu, Jr-Hsiung Jiang, WenJen Chang, "Scheduling a hybrid MTO/MTS semiconductor fab with machine-dedication features," Int. J. Production Economics, Vol. 112, pp. 416426, 2008.

[39] C.A. Soman_, D.P. van Donk, G.J.C. Gaalman, "Capacitated planning and scheduling for combined make-to-order and make-to-stock production in the food industry: An illustrative case study," Int.J. Production Economics, Vol.108, pp, 191199, 2007.

[40] In-Jae Jeong, "A dynamic model for the optimization of decoupling point and production planning in a supply chain," Int. J. Production Economics, Vol. 131, pp. 561-567, 2011.

[41] Sheng-Hung Chang, Ping-Feng Pai, KuoJung Yuan,Bo-Chang Wang, Rong-Kwei $\mathrm{Li}$, "Heuristic PAC model for hybrid MTO and MTS production environment, " Int. J. Production Economics, Vol. 85, pp. 347358,2003 .
[42]H. Eivazy \& M. Rabbani \& M. Ebadian, "A developed production control and scheduling model in the semiconductor manufacturing systems with hybrid maketo-stock/make-to-order products," Int J Adv Manuf Technol,Vol. 45, pp. 968986,2009.

[43] Khaled Youssef, Christian Delft, Yves Dallery, "Efficient Scheduling Rules in a Combined Make-to-Stock and Make-toOrder Manufacturing System," Annals of Operations Research, Vol. 126, pp. 103134, 2004

[44]Amr B. Eltawil, Rania M. Ghazal," Integrated Production-Inventory planning with make to order and make to stock considerations," The 36th CIE Conference on Computers and Industrial Engineering.

[45] Romain Guillaume, Bernard Grabot Caroline Thierry, "Management of the risk of backorders in a MTO-ATO/MTS context under imperfect requirements,"Applied Mathematical Modelling, Vol. 37, pp. 8060-8078, 2013. 